\title{
Noninvasive Ventilation Coupled With Nebulization During Asthma Crises: A Randomized Controlled Trial
}

\author{
Valdecir C Galindo-Filho MSc, Daniella C Brandão MSc, Rita de Cássia S Ferreira MSc, \\ Maria José C Menezes, Paulo Almeida-Filho MSc, Verônica F Parreira PhD, \\ Tayse N Silva MSc, Maria da Glória Rodrigues-Machado PhD, Elizabeth Dean PhD, \\ and Armèle Dornelas de Andrade PhD
}

\begin{abstract}
BACKGROUND: Despite the clinical improvements attributed to noninvasive ventilation (NIV) during asthma crises, and the well established effects of nebulization, there are few studies on the effects of these interventions together. We hypothesized that nebulization coupled to NIV should raise radio-aerosol pulmonary deposition in asthmatics. The aims of this study were to assess the effects of coupling $\beta$-agonist nebulization and NIV during asthma exacerbations on radio-aerosol pulmonary deposition, using scintigraphy and cardiopulmonary parameters, to correlate pulmonary function with radio-aerosol deposition index, radio-aerosol penetration index, and pulmonary clearance. METHODS: In this controlled trial, 21 adults with moderate to severe asthma attack were randomized to a control group $(n=11)$ or experimental group (NIV + nebulizer group, $n=10$ ). All subjects inhaled bronchodilators for 9 minutes, and after particles were counted with a gamma camera to analyze regions of interest and pulmonary clearance at $0,15,30,45$, and $60 \mathrm{~min}$. RESULTS: Breathing frequency $(P=<.001)$ and minute ventilation $(P=.01)$ were reduced, and tidal volume was increased $(P=.01)$ in the NIV + nebulizer group, compared with the control group. The NIV + nebulizer group had improvement from baseline values, compared to the control group in the following parameters: $\mathrm{FEV}_{1} 46.7 \pm 0.5 \%$ of predicted vs $29.8 \pm 8.9 \%$ of predicted, $P=.02)$, FVC $(41.2 \pm 1.5 \%$ of predicted vs $23.2 \pm 7.1 \%$ of predicted, $P=.02)$, peak expiratory flow $(67.3 \pm 38.3 \%$ of predicted vs $26.9 \pm 12.1 \%$ of predicted, $P=.01)$, and inspiratory capacity $(54.9 \pm 28.8 \%$ of predicted vs $31.2 \pm 9.1 \%$ of predicted, $P=.01)$. No differences were observed between groups regarding radio-aerosol deposition index or pulmonary clearance. Negative correlations were found between $\mathrm{FEV}_{1}$, forced expiratory flow during the middle half of the FVC maneuver ( $\left.\mathbf{F E F}_{25-75 \%}\right)$, inspiratory capacity, and radio-aerosol penetration index. CONCLUSIONS: Coupling nebulization and NIV during asthma exacerbation did not improve radio-aerosol pulmonary deposition, but we observed clinical improvement of pulmonary function in these subjects. (ClinicalTrials.gov registration NCT01012050) Key words: noninvasive ventilation; asthma; nebulization; pulmonary scintigraphy; radio-aerosol; pulmonary function. [Respir Care 2013;58(2):241-249. (C) 2013 Daedalus Enterprises]
\end{abstract}

\section{Introduction}

Asthma is highly prevalent worldwide and exacerbations can lead to acute respiratory failure. ${ }^{1-3}$ The first line

Mr Galindo-Filho, Ms Brandão, Ms Ferreira, Ms Silva, and Dr Dornelas de Andrade are affiliated with the Department of Physiotherapy, Universidade Federal de Pernambuco, Recife, Brazil. Ms Menezes and Mr Almeida-Filho are affiliated with the Department of Nuclear Medi- of treatment for asthma exacerbations is nebulization with $\beta$ agonists in order to reverse the bronchospasm. ${ }^{2,4-8}$

\footnotetext{
cine, Hospital Português, Recife, Brazil. Dr Parreira is affiliated with the Universidade Federal de Minas Gerais, Minas Gerais, Brazil. Dr Rodrigues-Machado is affiliated with the Faculty of Ciências Médicas, Minas Gerais, Brazil. Dr Dean is affiliated with the University of British Columbia, Vancouver, Canada.
} 
The benefits of noninvasive ventilation (NIV) in the treatment of asthma include reduced work of breathing, improvements in oxygenation, increased peak expiratory flow (PEF) and $\mathrm{FEV}_{1},{ }^{9-16}$ and accelerated bronchodilation. ${ }^{17}$ Despite the clinical improvements attributed to NIV and the well established effects of nebulization, there are few studies addressing the use of both methods together. Such studies would help to elucidate whether or not the improved deposition of $\beta$ agonists with NIV enhances the effects of bronchodilators.

See the Related Editorial on Page 380

We found no studies involving the scintigraphic analysis of radio-aerosol deposition coupled with NIV during asthma crises. However, a previous study published by our group found lesser deposition after coupling NIV to nebulization in healthy subjects. ${ }^{18}$ However, we hypothesized that nebulization of bronchodilators coupled with NIV would increase pulmonary deposition in acute asthma, and thus improve clinical parameters, compared to nebulization alone.

The aims of the present study were to assess the effect of coupling nebulization with NIV during asthma crises on radio-aerosol lung deposition and cardiopulmonary parameters, and to correlate pulmonary function with the radioaerosol deposition index, radio-aerosol penetration index, and pulmonary clearance.

\section{Methods}

This work was performed at Professor Barros Lima Hospital and Português Hospital, Recife City, Brazil.

\section{Subjects and Study Design}

A controlled randomized trial was carried out in a public emergency room. Thirty-nine males and females, ages $18-65$ years, with acute asthma, were enrolled in the study.

\footnotetext{
Dr Dornelas de Andrade presented a version of this paper at the meeting of the European Respiratory Society, held September 12-15, 2009, in Vienna, Austria.

This research was partly supported by Coordenação de Aperfeiçoamento de Pessoal de Nível Superior and Conselho Nacional de Desenvolvimento Científico e Tecnológico. The authors have disclosed relationships with Kesa Sourcing and White Martins Gases Industriais.

Correspondence: Armèle Dornelas de Andrade PhD, Department of Physiotherapy, Universidade Federal de Pernambuco, Avenida Jornalista Aníbal Fernandes, Recife, Pernambuco 50670-901 Brazil. E-mail: armeledornelas@yahoo.com.
}

DOI: $10.4187 /$ respcare. 01371

\section{QUICK LOOK}

\section{Current knowledge}

Aerosol delivery of $\beta$ agonists for reversal of bronchospasm is the mainstay of treatment for asthma exacerbations. Application of noninvasive ventilation (NIV) in asthmatic exacerbations may reduce the work of breathing and improve bronchodilator delivery, but has not been shown to alter outcomes. The use of NIV coupled with aerosolized $\beta$ agonists has not been specifically evaluated in acute asthma.

\section{What this paper contributes to our knowledge}

The addition of aerosolized $\beta$ agonists to NIV during asthma exacerbation did not improve radio-aerosol pulmonary deposition. NIV use was associated with more efficient ventilation, a reduction in respiratory rate, and increased tidal volume.

Subjects were diagnosed by the attending physician, and inhaled salbutamol $(2.5 \mathrm{mg})$ and ipratropium bromide $(0.25 \mathrm{mg})$ according to prescription. Spirometry was performed after $30 \mathrm{~min}$ (Vitalograph 2120, Vitalograph, Buckingham, United Kingdom). ${ }^{10}$ A variance of $0.2 \mathrm{~L}$ was allowed between tests, and the average of 3 measurements was recorded. ${ }^{19}$

This study was approved by our human research ethics committee, and all subjects gave written informed consent after being fully informed about the protocol. The trial was registered in ClinicalTrials.gov according to the registration number NCT01012050.

\section{Inclusion and Exclusion Criteria}

The following were the inclusion criteria: moderate to severe asthma $\left(\mathrm{FEV}_{1}<60 \%\right.$ of predicted values), ${ }^{20,21}$ breathing frequency $>25$ breaths/min, more than one year elapsed since the diagnosis of asthma, current asthma attack lasting $<7$ days, and reversibility of $\mathrm{FEV}_{1} \leq 10 \%$ following administration of bronchodilator. On the other hand, exclusion criteria were smoking history, cardiopulmonary diseases (COPD, pneumonia, cardiac failure, myocardial infarction, pneumothorax) hyperthermia, indication for mechanical ventilation, hemodynamic instability (heart rate $>150$ beats/min and systolic blood pressure $<90 \mathrm{~mm} \mathrm{Hg}$ ), arrhythmia, changes in consciousness, pregnancy, and contraindications for use of NIV. ${ }^{11}$

\section{Procedures}

Subjects were randomly allocated, with the use of a computer program, into 2 groups. The control group consisted of subjects using nebulization alone (control), and 


\section{Noninvasive Ventilation Coupled With Nebulization During Asthma Crises}

the experimental group consisted of subjects receiving NIV coupled to nebulization (NIV + nebulizer group). Group allocation was assigned after admission, which prohibited blind allocation. For ethical reasons, no sham group was used.

The cardiopulmonary parameters were measured before and after inhalation protocol, and we considered the average obtained after 3 maneuvers from each parameter in both groups (breathing frequency, $\mathrm{S}_{\mathrm{pO}_{2}}$, tidal volume $\left[\mathrm{V}_{\mathrm{T}}\right]$, minute ventilation $\left[\dot{\mathrm{V}}_{\mathrm{E}}\right]$, heart rate, systolic blood pressure, diastolic blood pressure, and inspiratory capacity), using pulse oximetry (Active, Ecafix, São Paulo, Brazil), a manual pressure manometer (DS 44-11, Welch Allyn, Beaverton, Oregon), and a ventilometer (Wright Respirometer Mark 8, Ferraris Medical, London, United Kingdom). For inspiratory capacity, the reference values reported by Stocks and Quanjer were used. ${ }^{22}$

An established protocol was used for the radio-aerosol inhalation of diethylene triamine penta-acetic technetium (DTPA-Tc ${ }^{99 m}$ ) with radioactivity of 25 millicuries. ${ }^{23}$ The jet nebulizer (NS Products, São Paulo, Brazil) was positioned between the mask and exhalation orifice using a $\mathrm{T}$ piece, with particle size generation in the $5 \mu \mathrm{m}$ range (according to the manufacturer's information), and oxygen flow titrated at $7 \mathrm{~L} / \mathrm{min}$ (OXI, Biotecmed, São Paulo, Brazil) for 9 min (sufficient time to complete the dose). DTPA-Tc ${ }^{99 m}$ was added to the bronchodilator, and saline solution was used to complete $4 \mathrm{~mL} . \mathrm{V}_{\mathrm{T}}$ and inspiratory flow were measured at the 3rd, 6th, and 9th min by a flow sensor (TRACE-5, Intermed, São Paulo, Brazil) placed in the circuit without interruption of inhalation or affecting drug delivery. Bi-level positive airway pressure (BiPAP Synchrony, Respironics, Murrysville, Pennsylvania) was applied using a face mask (ComfortFull 2, Respironics, Murrysville, Pennsylvania) attached with straps. The pressures adjusted were $12 \mathrm{~cm} \mathrm{H}_{2} \mathrm{O}$ of inspiratory pressure and $5 \mathrm{~cm} \mathrm{H}_{2} \mathrm{O}$ of expiratory pressure at the beginning of the procedure. The control group performed inhalation using the same mask and straps as the NIV + nebulizer group.

Radioactivity counts were performed using a gamma camera (Forte, Adac Laboratories, Milpitas, California) at intervals of $0,15,30,45$, and $60 \mathrm{~min} .{ }^{18}$ Regions of interest were delimited based on a previous protocol. ${ }^{23}$ The radioaerosol deposition index was expressed as percentage and was calculated as the ratio of the count in each region of interest to the total count in each lung. The radio-aerosol penetration index for each lung was expressed as the ratio between the count in the central region to the count in the peripheral region, considering the sum of deposition in the intermediate and peripheral regions of interest:

Radio-aerosol penetration index $=$ central region/

$$
\text { peripheral region } \times 100
$$

Pulmonary clearance assessed the permeability of the epithelial alveoli barrier through images obtained at intervals of $0,15,30,45$, and $60 \mathrm{~min}$.

\section{Statistical Analysis}

The primary outcomes were radio-aerosol deposition index, radio-aerosol penetration index, and pulmonary clearance. Thus, spirometry and cardiopulmonary variables after and before one hour of inhalation protocol for both groups were considered as secondary outcomes. The sample size was based on a power of $90 \%, \alpha=.05$ and $\beta=.10$, using data from a previous study, ${ }^{18}$ and established a minimum of 7 individuals per group. The Kolmogorov-Smirnov and Levene tests were employed first. The paired Student $t$ test was used to analyze intragroup variance. The independent Student $t$ test was used to compare intra-group variance. Pulmonary clearance analysis was performed with multivariate analysis of variance. The Pearson correlation was used to compare the radioaerosol deposition index, radio-aerosol penetration index, and pulmonary clearance with pulmonary function. The results are expressed as mean $\pm \mathrm{SD}$, considering a 95\% CI $(P<.05)$.

\section{Results}

Thirty-nine subjects were admitted during the study, but 6 declined to participate, 5 did not meet the eligibility criteria (age and smoking history), 2 did not adapt to the NIV mask, and 5 did not complete the experiment. Thus, 21 subjects participated and were randomly allocated to the 2 groups, as shown in Figure 1. Subject characteristics (ie, anthropometric data and pulmonary function) were similar between groups, as presented in Table 1 .

\section{Cardiopulmonary Parameters}

There was a reduction in breathing frequency and $\dot{V}_{E}$ and an increase in $\mathrm{V}_{\mathrm{T}}$ and inspiratory capacity in the $\mathrm{NIV}+$ nebulizer group, in comparison to the control group, as shown in Table 2. No statistically significant differences were detected between groups with regard to heart rate, $\mathrm{S}_{\mathrm{pO}_{2}}$, systolic blood pressure, and diastolic blood pressure following intervention. There were percentage gains in $\mathrm{FEV}_{1}, \mathrm{FVC}$, and PEF in the NIV + nebulizer group, in comparison to the control group, as presented in Table 3 . No significant differences were detected between groups with regard to forced expiratory flow during the middle half of the FVC maneuver $\left(\mathrm{FEF}_{25-75 \%}\right) . \mathrm{V}_{\mathrm{T}}$ and inspiratory flow increased in the NIV + nebulizer group, in comparison to the control group: $\mathrm{V}_{\mathrm{T}} 1.0 \pm 0.39 \mathrm{~L}$ vs $0.6 \pm 0.20 \mathrm{~L}$ $(P=.01)$, inspiratory flow $47.4 \pm 11.1 \mathrm{~L} / \mathrm{min}$ vs $34.7 \pm 11.1 \mathrm{~L} / \mathrm{min}(P=.02)$. 


\section{Noninvasive Ventilation Coupled With Nebulization During Asthma Crises}

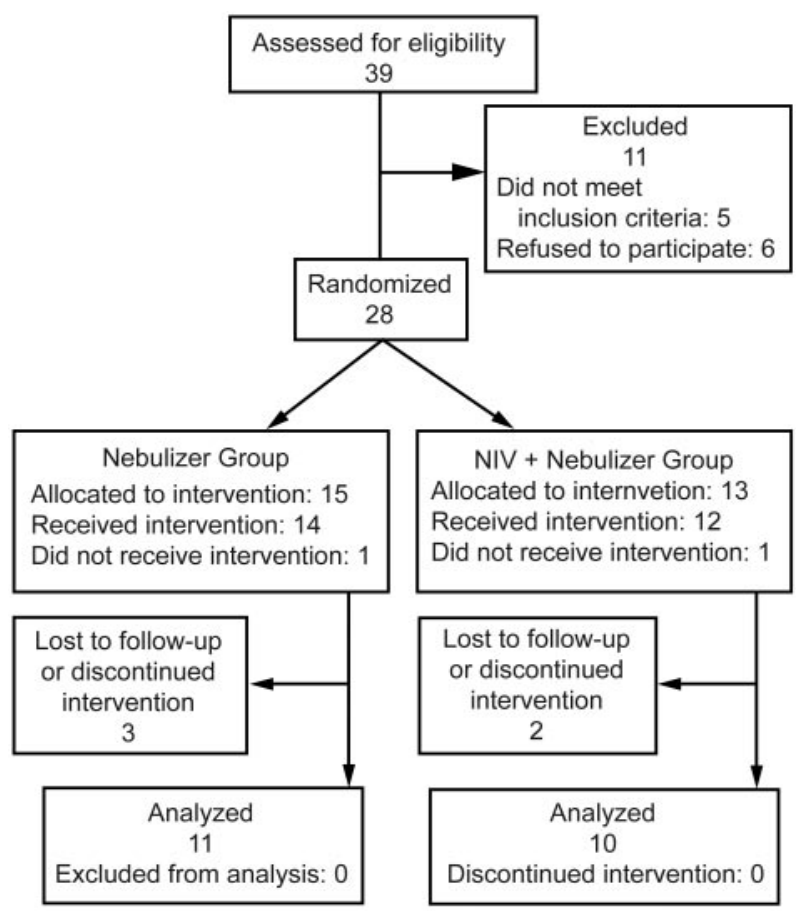

Fig. 1. Flow diagram of the study.

\section{Radio-aerosol Pulmonary Deposition}

There were no significant differences in radio-aerosol lung deposition between groups. The total amount of radio-aerosol particles deposited in the right lung was $216,058 \pm 56,462$ counts and 193,235 $\pm 115,501$ counts in the control and NIV + nebulizer groups, respectively. Regarding the left lung, the total amount of deposition reached was $173,626 \pm 69,835$ counts and $161,143 \pm$ 96,912 counts in the control and NIV + nebulizer groups, respectively.

Table 4 presents the results of the intra-group analysis of radio-aerosol deposition index with respect to the vertical and horizontal differences for each region of interest. There were intra-group differences, except when the upper and lower thirds of the left lung were compared in the $\mathrm{NIV}+$ nebulizer group. There was no difference in radioaerosol penetration index between groups, but there was a negative correlation between radio-aerosol penetration in-

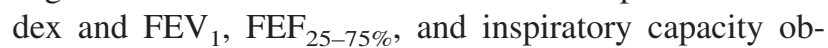
tained upon admission of the subjects in the control group, and $\mathrm{FEF}_{25-75 \%}$ in the left lung in the NIV + nebulizer group, as shown in Table 5. The analysis of qualitative radio-aerosol deposition revealed greater particle deposition in the central region in the right and left lungs in both groups, characterized by the presence of "hot spots," as shown in Figure 2. For the pulmonary clearance analysis, zero time was considered the first image obtained at the end of inhalation. After intervals of 15, 30, 45, and $60 \mathrm{~min}$,
Table 1. Anthropometric and Cardiopulmonary Characteristics

\begin{tabular}{|c|c|c|c|}
\hline & $\begin{array}{l}\text { Nebulizer } \\
\text { Control } \\
\text { Group } \\
(n=11)\end{array}$ & $\begin{array}{c}\text { NIV }+ \\
\text { Nebulizer } \\
\text { Group } \\
(n=10)\end{array}$ & $P$ \\
\hline Age, y & $44.2 \pm 10.3$ & $49.5 \pm 8.93$ & .58 \\
\hline Male/female, no. & $4 / 7$ & $2 / 7$ & \\
\hline BMI, $\mathrm{kg} / \mathrm{m}^{2}$ & $26.4 \pm 3.46$ & $27.9 \pm 4.76$ & .57 \\
\hline Breathing frequency, breaths/min & $29.2 \pm 1.40$ & $30.2 \pm 2.04$ & .22 \\
\hline $\mathrm{S}_{\mathrm{pO}_{2}}, \%$ & $95.4 \pm 1.74$ & $95.6 \pm 1.50$ & .69 \\
\hline $\mathrm{V}_{\mathrm{T}}, \mathrm{L}$ & $0.37 \pm 0.09$ & $0.35 \pm 0.07$ & .67 \\
\hline$\dot{\mathrm{V}}_{\mathrm{E}}, \mathrm{L}$ & $10.6 \pm 2.45$ & $10.7 \pm 2.23$ & .90 \\
\hline Heart rate, beats/min & $83.4 \pm 11.4$ & $79.2 \pm 12.79$ & .59 \\
\hline Systolic blood pressure, mm Hg & $126.4 \pm 16.4$ & $125.8 \pm 13.89$ & .50 \\
\hline Diastolic blood pressure, $\mathrm{mm} \mathrm{Hg}$ & $84.5 \pm 10.3$ & $81.0 \pm 10.22$ & .57 \\
\hline $\mathrm{FEV}_{1}, \%$ predicted & $44.2 \pm 18.7$ & $51.3 \pm 11.5$ & .44 \\
\hline $\mathrm{FEV}_{1}, \mathrm{~L}$ & $1.18 \pm 0.45$ & $1.28 \pm 0.23$ & .53 \\
\hline FVC, $\%$ predicted & $43.1 \pm 18.7$ & $50.2 \pm 11.3$ & .74 \\
\hline FVC, L & $1.49 \pm 0.52$ & $1.59 \pm 0.50$ & .73 \\
\hline PEF, \% predicted & $41.6 \pm 10.3$ & $40.4 \pm 9.7$ & .70 \\
\hline $\mathrm{PEF}, \mathrm{L} / \mathrm{min}$ & $158.7 \pm 45.55$ & $140.19 \pm 47.64$ & .49 \\
\hline $\mathrm{FEF}_{25-75 \%} \%$ predicted & $31.8 \pm 11.9$ & $38.5 \pm 7.2$ & .12 \\
\hline $\mathrm{FEF}_{25-75 \%,} \mathrm{~L}$ & $1.03 \pm 0.56$ & $1.20 \pm 0.44$ & .45 \\
\hline Inspiratory capacity, $\%$ predicted & $55.4 \pm 15.5$ & $59.9 \pm 15.8$ & .79 \\
\hline Inspiratory capacity, L & $1.16 \pm 0.37$ & $1.26 \pm 0.52$ & .38 \\
\hline $\begin{array}{l}\text { Except for male/female, the values are mean } \\
N I V=\text { noninvasive ventilation } \\
\mathrm{BMI}=\text { body mass index } \\
\mathrm{V}_{\mathrm{T}}=\text { tidal volume } \\
\dot{\mathrm{V}}_{\mathrm{E}}=\text { minute ventilation } \\
\mathrm{PEF}=\text { peak expiratory flow } \\
\mathrm{FEF}_{25-75 \%} \text { forced expiratory flow during t }\end{array}$ & he middle half of & C maneuver & \\
\hline
\end{tabular}

new images were taken in order to perform a temporal analysis. There was an intra-group count reduction in pulmonary clearance over time $(P=.82)$, but no difference was detected between groups.

To compare radio-aerosol deposition across time intervals, linear regression models were adjusted for each group and logarithmic equations were obtained:

$\log \mathrm{T}_{\text {clearance }}=12.57-0.0147 \times$ time

$$
\text { (NIV + nebulizer group) }
$$

in which $\log \mathrm{T}_{\text {clearance }}$ is a logarithm transformation in relation to the time of pulmonary clearance, and

$$
\log \mathrm{T}_{\text {clearance }}=12.78-0.0154 \times \text { time }(\text { control group })
$$

Based on these equations, mean radio-aerosol half-life was approximately $34 \mathrm{~min}$ in the NIV + nebulizer group and $39 \mathrm{~min}$ in the control group, as shown in Figure 3. Thus, Figure 4 illustrates the qualitative pulmonary clearance in subjects with different degrees of obstruction. 
Table 2. Ventilatory Data

\begin{tabular}{|c|c|c|c|}
\hline & $\begin{array}{c}\text { Nebulizer } \\
\text { Control } \\
\text { Group } \\
(n=11) \\
\end{array}$ & $\begin{array}{c}\text { NIV }+ \\
\text { Nebulizer } \\
\text { Group } \\
(n=10) \\
\end{array}$ & $P$ \\
\hline \multicolumn{4}{|l|}{$\mathrm{f}$, breaths/min } \\
\hline Before & $29.2 \pm 1.40$ & $30.2 \pm 2.04$ & .22 \\
\hline After & $21.1 \pm 2.21$ & $14.3 \pm 2.54$ & $<.001$ \\
\hline \multicolumn{4}{|l|}{$\mathrm{V}_{\mathrm{T}}, \mathrm{L}$} \\
\hline Before & $0.37 \pm 0.09$ & $0.35 \pm 0.07$ & .67 \\
\hline After & $0.46 \pm 0.08$ & $0.55 \pm 0.07$ & .01 \\
\hline \multicolumn{4}{|l|}{$\dot{\mathrm{V}}_{\mathrm{E}}, \mathrm{L}$} \\
\hline Before & $10.6 \pm 2.45$ & $10.7 \pm 2.23$ & .90 \\
\hline After & $9.65 \pm 1,63$ & $7.77 \pm 0.84$ & .006 \\
\hline $\begin{array}{l}\text { Values are mean } \pm \mathrm{S} D . \mathrm{I} \\
\text { samples. } \\
\mathrm{NIV}=\text { noninvasive venti } \\
\mathrm{f}=\text { breathing frequency } \\
\mathrm{V}_{\mathrm{T}}=\text { tidal volume } \\
\dot{\mathrm{V}}_{\mathrm{E}}=\text { minute ventilation }\end{array}$ & el of significance & ia Student $t$ test fo & ndent \\
\hline
\end{tabular}

Table 3. Pulmonary Function Test Data

\begin{tabular}{|c|c|c|c|}
\hline & $\begin{array}{l}\text { Nebulizer } \\
\text { Control } \\
\text { Group }\end{array}$ & $\begin{array}{l}\text { NIV }+ \\
\text { Nebulizer } \\
\text { Group }\end{array}$ & $P$ \\
\hline \multicolumn{4}{|l|}{$\mathrm{FEV}_{1}, \%$ predicted } \\
\hline Before & $44.2 \pm 18.7$ & $51.3 \pm 11.5$ & .44 \\
\hline After & $57.4 \pm 15.3$ & $75.3 \pm 15.7$ & $<.001$ \\
\hline Percent gain & $29.8 \pm 8.9$ & $46.7 \pm 0.5$ & .02 \\
\hline \multicolumn{4}{|l|}{ FVC, \% predicted } \\
\hline Before & $43.1 \pm 18.7$ & $50.2 \pm 11.3$ & .74 \\
\hline After & $53.1 \pm 12.8$ & $70.9 \pm 15.1$ & .006 \\
\hline Percent gain & $23.2 \pm 7.1$ & $41.2 \pm 1.5$ & .02 \\
\hline \multicolumn{4}{|l|}{ PEF, \% predicted } \\
\hline Before & $41.6 \pm 10.3$ & $40.4 \pm 9.7$ & .70 \\
\hline After & $52.8 \pm 9.9$ & $67.6 \pm 19.1$ & .04 \\
\hline Percent gain & $26.9 \pm 12.1$ & $67.3 \pm 38.3$ & .01 \\
\hline \multicolumn{4}{|l|}{$\begin{array}{c}\text { Inspiratory capacity, } \\
\% \text { predicted }\end{array}$} \\
\hline Before & $55.4 \pm 15.5$ & $59.9 \pm 15.8$ & .79 \\
\hline After & $72.7 \pm 16.9$ & $92,8 \pm 21.6$ & .02 \\
\hline Percent gain & $31.2 \pm 9.1$ & $54.9 \pm 28.8$ & .01 \\
\hline \multicolumn{4}{|c|}{$\begin{array}{l}\text { Values are mean } \pm \mathrm{S} D \text {. Level of significance } P<.05 \text { via Student } t \text { test for independent } \\
\text { samples. } \\
\text { NIV = noninvasive ventilation } \\
\text { PEF = peak expiratory flow }\end{array}$} \\
\hline
\end{tabular}

\section{Discussion}

This controlled randomized trial demonstrated that coupling nebulization with NIV during asthma exacerbations leads to an improvement of pulmonary function, specifically $\mathrm{FEV}_{1}, \mathrm{FVC}, \mathrm{PEF}, \mathrm{V}_{\mathrm{T}}, \dot{\mathrm{V}}_{\mathrm{E}}$, and inspiratory capacity. However, no difference in radio-aerosol pulmonary deposition was observed in either group.

During asthma attacks, patients experience an increase in work of breathing, reflected in a rise in breathing frequency, $\dot{\mathrm{V}}_{\mathrm{E}}$, and excessive recruitment of accessory muscles. ${ }^{9,14}$ In the present study, breathing frequency and $\dot{V}_{\mathrm{E}}$ decreased in the group using nebulized $\beta$ agonists coupled with NIV. These findings corroborate previous studies reporting a reduction in breathing frequency and respiratory muscle recruitment, as well as improved gas exchange in patients with asthma treated with NIV in emergency rooms or hospitals. ${ }^{9} 10,12,13,16,24-26$

There was also an increase in $\mathrm{V}_{\mathrm{T}}$ in the NIV + nebulizer group, when compared to the control group. This may be due to the benefits of inspiratory pressure, which diminishes muscle fatigue and dyspnea and improves $\mathrm{V}_{\mathrm{T}}$ due to the increase in ventilatory comfort. ${ }^{24}$

Regarding the spirometric data, FVC, $\mathrm{FEV}_{1}$, and PEF increased in the NIV + nebulizer group. Similar results were reported by Pollack et al, ${ }^{12}$ who found an increase in PEF in patients with asthma after delivering $\beta$ agonists through bi-level positive airway pressure, when compared to the group that received only nebulization. However, the methodology employed by the authors did not elucidate whether the increase in PEF was due to mechanical bronchodilation or greater drug deposition. In a recent study published by our group, Brandão et $\mathrm{al}^{26}$ reported a reduction in bronchial obstruction and symptoms secondary to augmented PEF after coupling nebulization with NIV in individuals with asthma.

Soroksky et al ${ }^{10}$ administered NIV alone using bi-level positive airway pressure on patients with asthma, and observed improvements in the spirometric data, as well as the relief of respiratory discomfort and a reduction in the intubation rate. These results could be explained by the alleviation of the load imposed on the inspiratory muscles and the direct bronchodilator effect of NIV, thereby diminishing intrinsic PEEP and favoring the recruitment of collapsed alveolar units. Soma et al ${ }^{15}$ administered bi-level positive airway pressure for $40 \mathrm{~min}$ to patients with mild to moderate asthma and found improved pulmonary function and the relief of respiratory discomfort when using lower pressure levels. The fact that these studies did not administer NIV coupled to nebulization limits comparisons to our findings. Thus, to our knowledge, our study is the first controlled randomized trial using simultaneous NIV and nebulization.

There was a greater increase in inspiratory capacity in the group that received NIV + nebulizer. A number of studies have demonstrated inspiratory capacity gains in patients with COPD (ie, reduced dynamic hyperinflation) after treatment with drugs or pulmonary rehabilitation. ${ }^{27,28}$ The higher percentage gain in inspiratory capacity was likely due to a decrease in inspiratory muscle load as a 


\section{Noninvasive Ventilation Coupled With Nebulization During Asthma Crises}

Table 4. Radio-Aerosol Deposition Index Differences

\begin{tabular}{|c|c|c|c|c|c|}
\hline & \multirow{2}{*}{ Group } & \multicolumn{2}{|c|}{ Vertical Differences } & \multicolumn{2}{|l|}{ Horizontal Differences } \\
\hline & & Lung Region & $P$ & Lung Region & $P$ \\
\hline \multirow[t]{6}{*}{ Right lung } & Nebulizer & Upper third $<$ middle third & $<.001$ & Central third $>$ intermediate third & .02 \\
\hline & & Upper third $<$ lower third & $<.001$ & Central third $>$ peripheral third & $<.001$ \\
\hline & & Middle third $>$ lower third & .02 & Intermediate third $>$ peripheral third & $<.001$ \\
\hline & NIV + nebulizer & Upper third $<$ middle third & $<.001$ & Central third $>$ intermediate third & .01 \\
\hline & & Upper third $<$ lower third & .007 & Central third $>$ peripheral third & $<.001$ \\
\hline & & Middle third $>$ lower third & .007 & Intermediate third $>$ peripheral third & $<.001$ \\
\hline \multirow[t]{6}{*}{ Left lung } & Nebulizer & Upper third $<$ middle third & .002 & Central third $>$ intermediate third & .004 \\
\hline & & Upper third $=$ lower third & .52 & Central third $>$ peripheral third & $<.001$ \\
\hline & & Middle third $>$ lower third & .001 & Intermediate third $>$ peripheral third & $<.001$ \\
\hline & NIV + nebulizer & Upper third $<$ middle third & $<.001$ & Central third $>$ intermediate third & $<.001$ \\
\hline & & Upper third $<$ lower third & .01 & Central third $>$ peripheral third & $<.001$ \\
\hline & & Middle third $>$ lower third & .02 & Intermediate third $>$ peripheral third & $<.001$ \\
\hline
\end{tabular}

Values are given as mean $\pm \mathrm{SD}$. Level of significance $P<.05$ via Student $t$ test for independent samples.

$\mathrm{NIV}=$ noninvasive ventilation

Table 5. Correlation of Radio-Aerosol Penetration Index, Pulmonary Function, and Inspiratory Capacity

\begin{tabular}{|c|c|c|c|c|c|}
\hline \multirow{2}{*}{ Group } & \multirow{2}{*}{ Variables } & \multicolumn{2}{|c|}{$\begin{array}{l}\text { Pearson Correlation } \\
\text { Coefficient }(\mathrm{r})^{*}\end{array}$} & \multicolumn{2}{|c|}{$P$} \\
\hline & & Right Lung & Left Lung & Right Lung & Left Lung \\
\hline \multirow[t]{3}{*}{ Nebulizer } & $\mathrm{FEV}_{1}$ & -0.784 & -0.656 & .004 & .03 \\
\hline & $\mathrm{FEF}_{25-57 \%}$ & -0.709 & -0.623 & .02 & .04 \\
\hline & Inspiratory capacity & -0.914 & -0.788 & $<.001$ & .004 \\
\hline NIV + nebulizer & $\mathrm{FEF}_{25-57 \%}$ & & -0.742 & & .01 \\
\hline
\end{tabular}

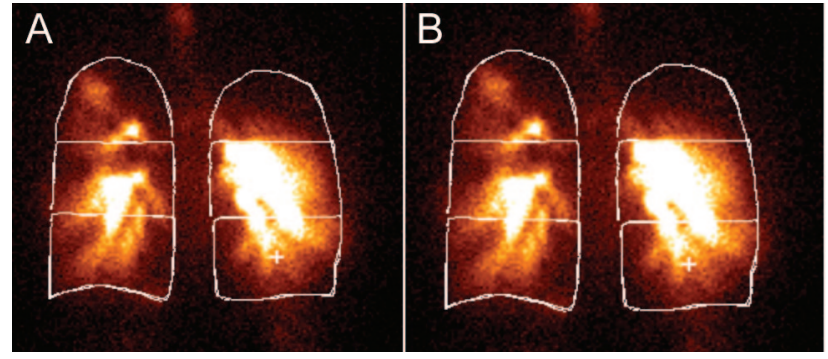

Fig. 2. Heterogeneous deposition pattern in scintigraphic images of subjects with asthma, with a predominance of radio-aerosol deposition in the central region in a subject in the control group $(A)$ and another in the noninvasive ventilation + nebulizer group (B).

consequence of the expiratory pressure applied to reduce air trapping, with a decrease in intrinsic PEEP and an increase in inspiratory capacity.

No reports were found in the literature on the distribution of ventilation assessed by scintigraphy on patients with asthma involving NIV and nebulization simultaneously. However, a decrease in peripheral aerosol deposition, with greater particle impaction in the upper airways, has been reported in patients with stable chronic bronchitis using intermittent positive-pressure breathing, in comparison to nebulization during spontaneous breathing. ${ }^{29}$ On the other hand, a 30\% increase in radio-aerosol deposition without impaction in the proximal airways during application of NIV has been observed in children with cystic fibrosis. ${ }^{30}$

In the present study, no difference was found in radioaerosol deposition between groups. Comparisons to the studies described above are limited due to the pathological conditions of the present sample. A previous study conducted by our group on healthy subjects found greater radio-aerosol deposition in the group that nebulized only, when compared to the group that received nebulization through bi-level positive airway pressure. Thus, the study also reports a correlation between particle counts and $\mathrm{V}_{\mathrm{T}}$, 


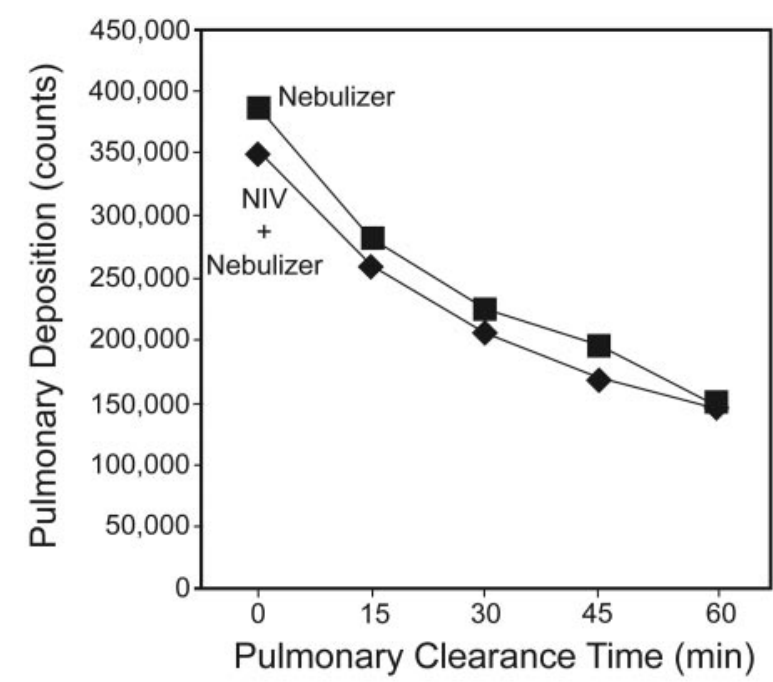

Fig. 3. Radio-aerosol lung deposition (counts) based on lung clearance time in both groups of subjects with asthma treated in the emergency room. Analysis of variance was performed to compare both groups with repeated measurements, and no difference was found between them.

with a lower inspiratory flow $(25 \mathrm{~L} / \mathrm{min})$, which may have increased the ventilation distribution. ${ }^{18}$

Several factors can influence aerosol deposition, and inspiratory flow is an important determinant of particle transport and deposition. Higher flows could lead to greater aerosol impaction in the upper and central airways, as turbulent flows produce strong inertial forces that impact aerosols in the proximal airways. ${ }^{31-33}$ Inspiratory flow and $\mathrm{V}_{\mathrm{T}}$ were monitored during inhalation, and an increase in these variables was observed in the NIV + nebulizer group, when compared to the control group. Both groups had an inspiratory flow above $30 \mathrm{~L} / \mathrm{min}$, favoring greater penetration of radio-aerosol in the central airways. Previous studies described similar results, with flow values of around $40 \mathrm{~L} / \mathrm{min}$ contributing to less peripheral deposition. ${ }^{18,33}$

The analysis of deposition in the vertical differences revealed greater deposition in the middle third in comparison to the upper and lower thirds, and in the lower third, in comparison to the upper third, in both lungs. However, no difference in radio-aerosol counts was detected between the upper and lower thirds of the left lung in the control group. This regional difference could be attributed to the vertical difference between the base and apex of the lung, which are in different positions on the pressure-volume curve. ${ }^{34}$ This should be explained by the scintigraphic images obtained from asthmatics that showed a different deposition pattern, which suggests that obstruction level can affect pulmonary segments differently.

Irregular deposition pattern observed in the images suggests that obstruction may affect pulmonary segments in a variable manner. Another consideration that explains the

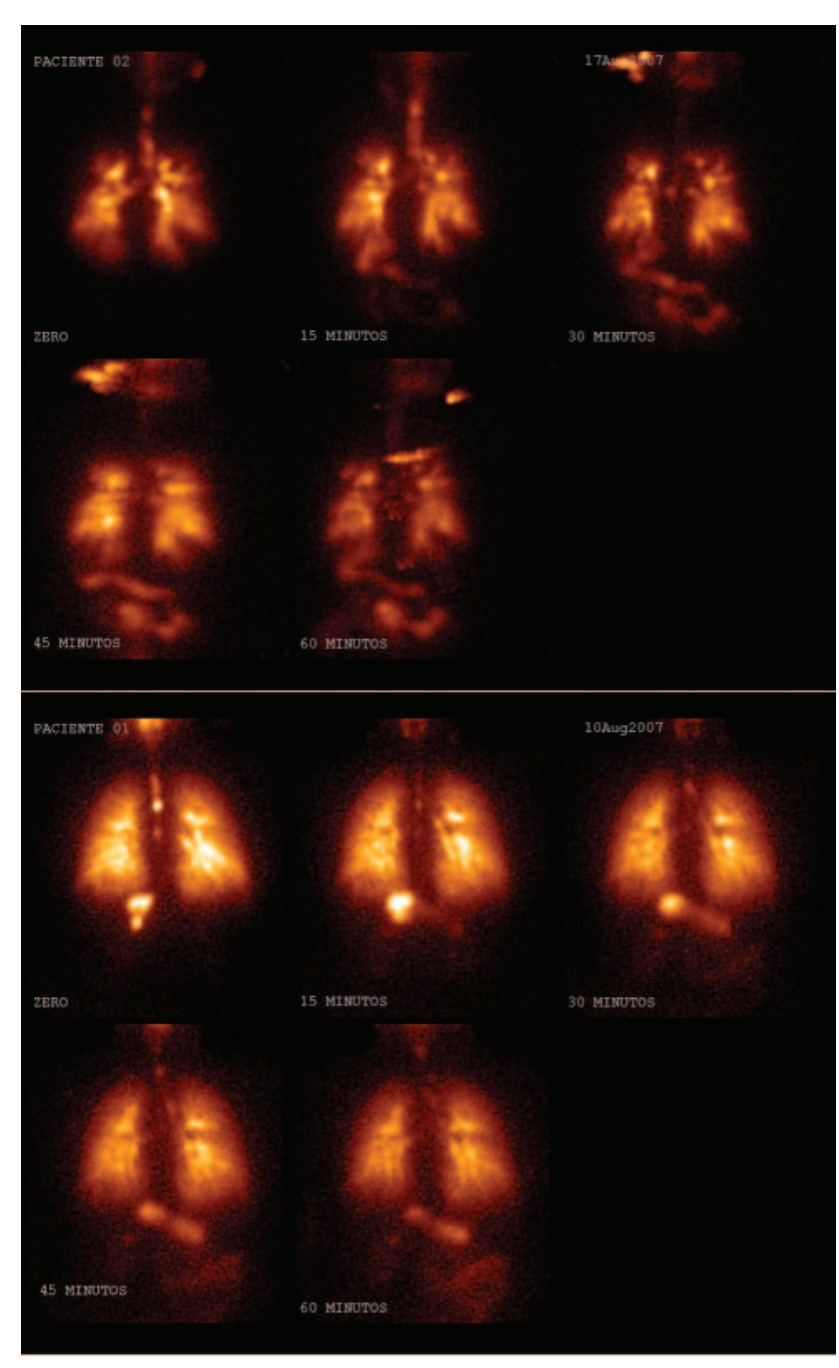

Fig. 4. Images taken during pulmonary clearance of subjects with asthma whose crisis classification was severe $(A)$ and moderate $(B)$.

highest deposition is that central airways are located in the middle third, and aerosol was deposited more centrally.

Regarding deposition in the horizontal differences, greater deposition occurred in the central region, when compared to the intermediate and peripheral regions. In regions with mild to severe obstruction, increased velocity and turbulent flows seem to promote deposition through the impaction mechanism, resulting in a concentration of radio-aerosol in "hot spots" near the obstructed areas. ${ }^{33}$

The radio-aerosol penetration index was higher in the central regions of the lungs in both groups, thereby reducing the percentage that reached the intermediate and peripheral regions. Fauroux et $\mathrm{al}^{33}$ found a higher radioaerosol penetration index in the NIV + nebulizer group, but the comparison of those data to our results is limited, as the patients assessed in the Fauroux et al study had cystic fibrosis, and the obstruction measured by the spirometry differed from those patients with asthma. 


\section{Noninvasive Ventilation Coupled With Nebulization During Asthma Crises}

The analysis of radio-aerosol penetration index in relation to spirometric parameters and inspiratory capacity revealed a negative correlation to $\mathrm{FEV}_{1}, \mathrm{FEF}_{25-75 \%}$, and inspiratory capacity in the control group and only to $\mathrm{FEF}_{25-57 \%}$ in the NIV + nebulizer group. The NIV + nebulizer group probably presented less correlation between radio-aerosol penetration index and lung function because NIV itself improved lung function substantially, which obscured the response from regional deposition aerosol.

According to pulmonary clearance, radio-aerosol particles can be eliminated through the respiratory epithelium, mucociliary clearance, and coughing, which are related to the particle deposition site. ${ }^{35}$ DTPA-Tc ${ }^{99 m}$ was used in the present study, which is cleared through the alveolarcapillary membrane, with a mean biologic half-life of approximately $60 \mathrm{~min}$. Mean radio-aerosol half-life did not achieve statistical significance and the data were similar in both groups, possibly due to the bronchial obstruction in patients with asthma, leading to a reduction in radioaerosol deposition in the peripheral airways. Thus, when bronchodilators are administered during an asthma crisis, pulmonary clearance time should be considered, given that it may influence the response.

Some limitations should be considered when interpreting the results of this study. First, no validated protocols were found in the literature consulted concerning the application of bi-level inspiratory and expiratory pressures in patients with asthma. For this reason, the decision was made to use the values reported in a previous study published by our group. Second, there was no determination of the extent to which this response improves other clinical outcomes, such as stay in the emergency room and hospitalization rates.

\section{Conclusions}

Finally, to our knowledge this is the first study to couple nebulization and NIV through scintigraphy in the treatment of asthma exacerbations, and we conclude that:

- NIV did not increase aerosol deposition or improve penetration index.

- It is technically feasible to deliver aerosol effectively during NIV in asthmatics.

- NIV has additive benefits to the treatment of acute asthma, as measured by the acute changes in respiratory variables.

Further studies are necessary to see if NIV reduces hospitalization rates from the emergency room, or reduces length of hospital stay.

\section{ACKNOWLEDGMENTS}

The authors are grateful to Dr Cristiana Almeida for granting use of the Real Nuclear for the scintigraphic examinations, and Kesa Sourcing and White Martins Gases Industriais for the devices for positive pressure and monitoring respiratory parameters. Our sincere thanks go to Dr Eduardo Ériko Tenório de França for his valuable suggestions regarding the methodology used in the study.

\section{REFERENCES}

1. Bateman ED, Hurd SS, Barnes PJ, Bousquet J, Drazen JM, FitzGerald $\mathrm{M}$, et al. Global strategy for asthma management and prevention: GINA executive summary. Eur Respir J 2008;31(1):143-178.

2. Rodrigo GJ, Rodrigo C, Hall JB. Acute asthma in adults: a review. Chest 2004;125(3):1081-1102.

3. Rowe BH, Voaklander DC, Wang D, Senthilselvan A, Klassen TP, Marrie TJ, et al. Asthma presentations by adults to emergency departments in Alberta, Canada: a large population-based study. Chest 2009;135(1):57-65.

4. Brasson SS. The global burden of asthma. Chest 2006;130(1):4S$12 \mathrm{~S}$

5. Dolovich MB, Ahrens RC, Hess DR, Anderson P, Dhand R, Rau JL, et al. Device selection and outcomes of aerosol therapy: evidencebased guidelines. American College of Chest Physicians/American College of Asthma, Allergy and Immunology. Chest 2005;127(1): 335-371.

6. Hanania NA, Moore RH, Zimmerman JL, Miller CT, Bag R, Sharafkhaneh A, et al. The role of intrinsic efficacy in determining response to a $\beta_{2}$-agonist in acute severe asthma. Respir Med 2007; 101(5):1007-1014

7. Blake K, Madabushi R, Derendorf H, Lima J. Population pharmacodynamic model of bronchodilator response to inhaled albuterol in children and adults with asthma. Chest 2008;134(5):981-989.

8. Rau JL. The inhalation of drugs: advantages and problems. Respir Care 2005;50(3):367-382.

9. Meduri GU, Cook TR, Turner RE, Cohen M, Leeper KV. Noninvasive positive pressure ventilation in status asthmaticus. Chest 1996; 110(3):767-774.

10. Soroksky A, Stav D, Shpirer I. A pilot prospective, randomized, placebo-controlled trial of bilevel positive airway pressure in acute asthmatic attack. Chest 2003;123(4):1018-1025.

11. Metha S, Hill NS. State of the art: noninvasive ventilation. Am J Respir Crit Care Med 2001;163(2):540-577.

12. Pollack CV, Fleisch KB, Dowsey K. Treatment of acute bronchospasm with $\beta$-adrenergic agonist aerosols delivered by a nasal bilevel positive airway pressure circuit. Ann Emerg Med 1995;26(6):552-557.

13. Thill PJ, McGuire JK, Baden HP, Green TP, Checchia PA. Noninvasive positive pressure ventilation in children with lower airway obstruction. Pediatr Crit Care Med 2004;5(4):337-342.

14. Carroll CL, Schramm CM. Noninvasive positive pressure ventilation for the treatment of status asthmaticus in children. Ann Aller Asthma Immunol 2006;96(3):454-459.

15. Soma T, Hino M, Kida K, Kudoh S. A prospective and randomized study for improvement of acute asthma by non-invasive positive pressure ventilation (NPPV). Intern Med 2008;47(6):493-501.

16. Gupta D, Nath A, Agarwal R, Behera D. A prospective randomized controlled trial on the efficacy of noninvasive ventilation in severe acute asthma. Respir Care 2010;55(5):536-543.

17. Scala R. Noninvasive ventilation in severe acute asthma? Still far from the truth (editorial). Respir Care 2010;55(5):630-637.

18. França EE, Dornelas de Andrade AF, Cabral G, Almeida Filho P, Silva KC, Galindo Filho VC, et al. Nebulization associated with bi-level noninvasive ventilation: analysis of pulmonary radio aerosol deposition. Respir Med 2006;100(4):721-728. 


\section{Noninvasive Ventilation Coupled With Nebulization During Asthma Crises}

19. American Thoracic Society. Standards for the diagnosis and care of patients with chronic obstructive pulmonary disease. Am J Respir Crit Care Med 1995;152(5 Pt 2):S77-S120.

20. Sociedade Brasileira de Pneumologia e Tisiologia. IV Diretrizes Brasileiras para o manejo da asma. J Bras Pneumol 2006;32(Suppl 7):S447-S474. Article in Portuguese.

21. Pereira CAL, Barreto SP, Simões JG. Valores de referência para espirometria de uma amostra da população brasileira adulta. J Pneumologia 1992;18(1):10-22. Article in Portuguese.

22. Stocks J, Quanjer PH. Reference values for residual volume, functional residual capacity and total lung capacity. ATS Workshop on lung volume measurements. Official statement of the European Respiratory Society. Eur Respir J 1995;8(3):492-506.

23. Nobre MEP, Lopes F, Cordeiro L, Marino PE, Silva TN, Amorim C. Inspiratory muscle endurance testing: pulmonary ventilation and electromyographic analysis. Respir Physiol Neurobiol 2007;155(1): 41-48.

24. Shirivam U, Donath J, Khan FA, Julianao J. Effects of continuous positive airway pressure in acute asthma. Respiration 1987;52(3): 157-162.

25. Beers SL, Abramo TJ, Bracken A, Wiebe RA. Bilevel positive airway pressure in the treatment of status asthmaticus in pediatrics. Am J Emerg Med 2007;25(1):6-9.

26. Brandão DC, Lima VM, Galindo Filho VC, Silva TN, Campos TF, Dean E, et al. Reversal of bronchial obstruction with bi-level positive airway pressure and nebulization in patients with acute asthma. J Asthma 2009;46(4):356-361.
27. Celli B, ZuWallack R, Wang S, Kesten S. Improvement in resting inspiratory capacity and hyperinflation with tiotropium in COPD patients with increased static lung volumes. Chest 2003;124(5): 1743-1748.

28. Casaburi R, Porszasz J. Reduction of hyperinflation by pharmacologic and other interventions. Proc Am Thorac Soc 2006;3(2): 185-189.

29. Dolovich M, Killian D, Wolff RK, Obminski G, Newhouse MT. Pulmonary aerosol deposition in chronic bronchitis: intermittent positive pressure breathing versus quiet breathing. Am Rev Respir Dis 1977;115(3):397-402.

30. Fauroux B, Itti E, Pegeot J, Isabey D, Meignan M, Ferry G, et al. Optimization of aerosol deposition by pressure support in children with cystic fibrosis: an experimental and clinical study. Am J Respir Crit Care Med 2000;162(6):2265-2271.

31. Newman SP, Woodman G, Clarke SW. Deposition of carbenicillin aerosols in cystic fibrosis: effects of nebuliser system and breathing pattern. Thorax 1988;43(4):318-322.

32. Hess DR, Fischer D, Williams P, Pooler S, Kacmarek RM. Medication nebulizer performance. Effects of diluent volume, nebulizer flow, and nebulizer brand. Chest 1996;110(2):498-505.

33. Fauroux B, Boulé M, Lofaso F, Zérah F, Clément A, Harf A, et al Chest physiotherapy in cystic fibrosis: improved tolerance with nasal pressure support ventilation. Pediatrics 1999;103(3):e32.

34. Hayes M, Taplin GV. Lung imaging with radioaerossols for the assessment of airway disease. Semin Nucl Med 1980;10(3):243-250.

35. O'Doherty MJ, Miller RF. Pulmonary nuclear medicine. Eur J Nuclear Med 1992;19(5):586-589.

This article is approved for Continuing Respiratory Care Education credit. For information and to obtain your CRCE

(free to AARC members) visit

www.rcjournal.com 